УДК 634.222:631.51

\title{
ВЛИЯНИЕ ПОСЛЕУБОРОЧНОЙ ОБРАБОТКИ ПРЕПАРАТОМ ФИТОМАГ НА ЛЕЖКОСТЬ ПЛОДОВ СЛИВЫ ПОЗДНИХ СОРТОВ
}

Маринеску Марина Федоровна к.б.н., ведущий научный сотрудник

Гавюк Людмила Алексеевна Бежан Нина Андреевна научные сотрудники Институт генетики, физиологии и защиты растений АН Молдовы

Аннотация: Проведены исследования по влиянию обработки ингибирующим биосинтез этилена препаратом Фитомаг на показатели качества и длительность хранения плодов сливы позднего сорта Президент. Установлено, что применяемая обработка повышает товарные качества (твердость, сочность и тургор клеток плода), а также лежкость плодов сливы при длительном хранении.

Ключевые слова: плоды сливы, хранение, Фитомаг, цитология, биохимия.

\section{INFLUENCE OF POST-HARVEST TREATMENT WITH PHYTOMAG ON STORABILITY OF PLUM FRUITS}

\author{
Marinescu Marina Fyodorovna \\ Gavyuk Lyudmila Alekseevna \\ Bezhan Nina Andreevna
}

\begin{abstract}
Studies have been carried out on the effect of treatment with the inhibitor of ethylene biosynthesis Fitomag on the quality indicators and storage duration of the fruits of the plum variety President. It was found that the applied treatment increases the commercial qualities (hardness, juiciness and turgor of the fruit cells), as well as the keeping quality of plum fruits during long-term storage.
\end{abstract}

Key words: fruit of plum, storability, Phytomag, cytology, biochemistry 


\section{Введение}

Обеспечение потребительского рынка качественными свежими фруктами предусматривает применение современных приемов и методов хранения. После сбора урожая продукция подвергается негативному влиянию абиотических и биотических факторов, которые могут повлиять на конечное качество плодов [1, с. 48]. Физиолого-биохимические изменения, происходящие в послеуборочный период, непосредственным образом отражаются на качестве плодов, продолжительность хранения которых коррелирует с интенсивностью обменных процессов [2, с. 121].

Эффективность обработки плодов ингибиторами синтеза этилена изучается достаточно давно и подтверждена рядом исследований [3, с. $73 ; 4$, с. $135 ; 5$, с. 140]. При этом вопросы ее влияния на качество, структуру и биохимический состав плодов, а также на длительность их хранения остаются недостаточно изученными.

Целью данного исследования было выявление влияния послеуборочной обработки препаратом Фитомаг на структурные и биохимические изменения в перикарпии плодов сливы сорта Президент в процессе хранения.

\section{Материалы и методика}

Объектом исследования служили плоды сливы позднего сорта Президент из плодового сада Научно-практического института садоводства и пищевых технологий. Плоды хранили в течение 110 дней, при температуре $1^{0} \mathrm{C}$ в обычной атмосфере (OA), и в РГС при температуре $+2 \mathrm{C}^{0}$. Опытную партию плодов однократно обрабатывали препаратом Фитомаг (1-метилциклопропен) с нормой расхода: 0,1 г/куб. м.

Анатомические исследования проводили на свежем материале согласно общепринятым методикам [6, с. 97; 7, с. 52] непосредственно после отбора плодов. Препараты изучали при помощи светового микроскопа Биолар-И. Измерения производили с помощью окуляр-микрометра при увеличении объектива 10x и 40x.

Определяли толщину кутикулы, высоту клеток эпидермиса, число слоев гиподермы, толщину слоя гиподермы, общую толщину кожицы и размеры клеток основной паренхимы.

Определение содержания углеводов и титруемых кислот проводили по методике Арасимович В.В., Пономаревой Н.П. [8, с.69].

\section{Результаты и обсуждение}

Плоды сливы сорта Президент крупные (50-60 г), округлой формы, с закругленной верхушкой и углублением в основании. Кожица средней 
толщины, с малозаметным неглубоким брюшным швом, от мякоти отделяется с трудом. Окраска плодов - от пурпурной до фиолетовой, с густым синеватым налётом воска. По всей поверхности неравномерно распределены слабо различимые под слоем воска различимые мелкие чечевички светло-бурого цвета. Мякоть окрашена в желто-зеленый или желтый цвет, окраска полости одноцветная с мякотью. Плоды созревают в первой-второй декаде сентября. Урожайность и транспортабельность плодов достаточно высокая. Сохранность в холодильнике в обычной атмосфере до 35-45 дней.

Плоды исследуемого сорта характеризуются наличием кристаллическоламеллярной кутикулы средней толщины (9-12 $\mu \mathrm{m})$, проникающей на 2/3 высоты клеток эпидермиса, а иногда и глубже (до гиподермы). Толщина слабо структурированного эпикутикулярного воска достигает 2,0 $\mu \mathrm{m}$. Восковой налет плодов отличается уплотненной однородной структурой с многочисленными зернистыми включениями в зоне соприкосновения со стенками клеток эпидермиса.

Эпидермис (22-28 $\mu \mathrm{m})$ - однорядный, состоит из прямоугольных клеток с высокой степенью компактизации. Гиподерма, как правило, состоит из 6 рядов тангентально-удлиненных крупных клеток с толстыми стенками (до 1,72,0 $\mu \mathrm{m})$. Мезокарпий сформирован из овальных и радиально-удлиненных клеток.

В процессе длительного хранения плодов имеет место гидролиз запасных питательных веществ [9, с.132]. В заложенных на хранение в ОА, РГС и при обработке Фитомагом плодах сливы изменения, происходящие в тканях, протекают различными темпами. При хранении в ОА клеточные стенки истончаются и объемы межклетников увеличиваются в большей степени. Обработки Фитомагом, позволяет сохранить целостность воскового налета, начало деградации воска наблюдалось после полутора месяцев хранения в ОА и через 55-60 дней в варианте с Фитомагом. В варианте хранения плодов в РГС эти изменения наблюдали после 65 дней хранения, что в принципе вполне сопоставимо с результатами, полученными в результате обработки ингибитором синтеза этилена.

В партиях плодов, обработанных Фитомагом, все биохимические процессы протекают менее интенсивно [3, с.74].

Преждевременная мацерация тканей, выражающаяся в разрушении серединных пластинок между клеточными оболочками под действием ферментов, тормозится при помощи препарата Фитомаг. При хранении плодов, обработанных указанным веществом клетки основных подзон 48 
паренхимы, практически до конца срока хранения сохраняли четкие контуры, при этом ткани плода характеризовались наличием незначительного числа мелких (до 10-12 $\mu \mathrm{m}$ ) межклетников. В то же время образцы, хранившиеся в OA, характеризовались более интенсивной мацерацией клеток, сопровождающейся увеличением объема межклетников (по сравнению с исходными значениями) и их размеров (до 20-35 $\mu \mathrm{m}$ ). Обработка ингибитором этилена позволила замедлить процессы гидролиза и сохранить содержание полисахаридов в клетках на более высоком уровне.

Анатомические исследования в полной мере согласуются с данными, полученными при изучении протекающих в плодах биохимических процессов.

На протяжении всего периода хранения оценивали динамику изменения основных показателей качества плодов - содержания сухого вещества, углеводов, титруемых кислот, витамина С и сахаро/кислотного индекса (гармония вкуса).

Наименьшее изменение содержания биохимических веществ наблюдали в варианте хранения плодов сливы подвергшихся обработке препаратом Фитомаг (рис.1). Полученные показатели в данном варианте практически не отличались от данных в варианте хранения плодов изученного сорта в РГС.

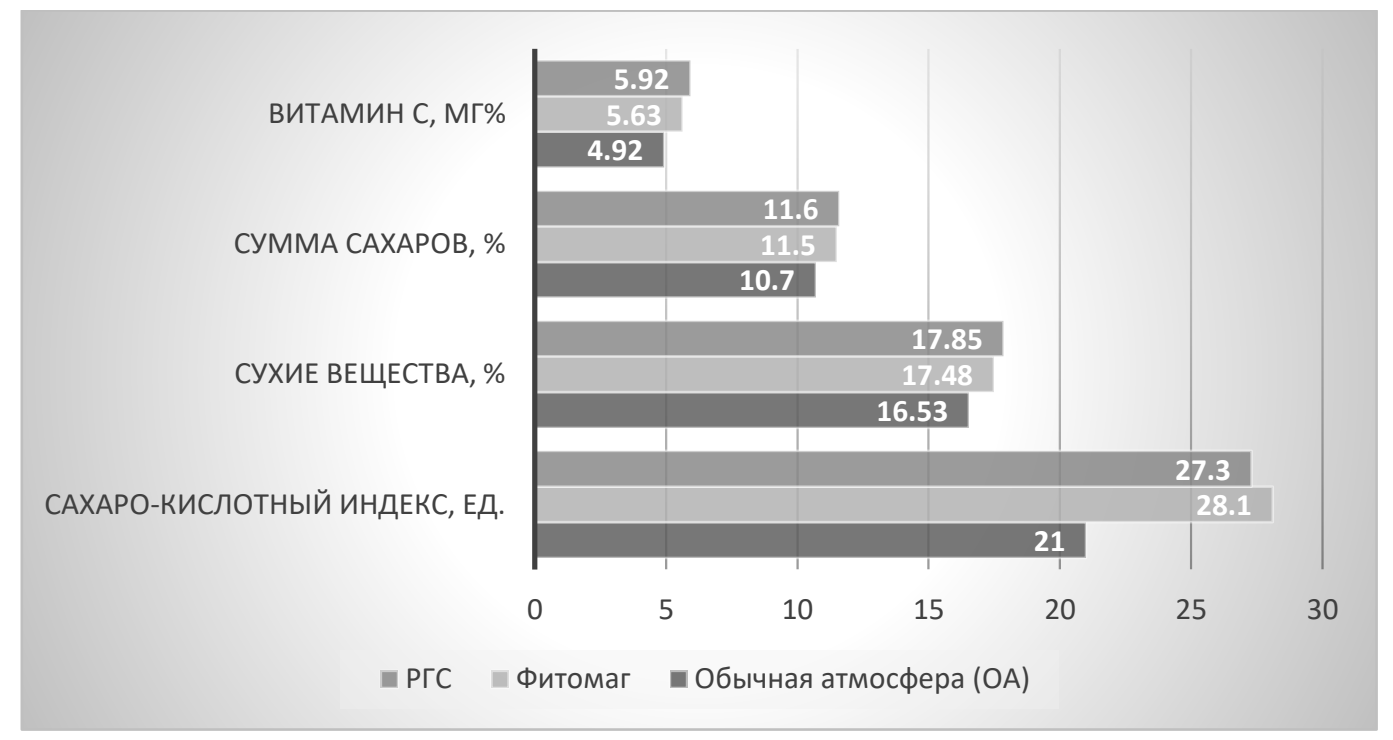

\section{Рис.1. Биодеградация пластических веществ в зависимости от метода хранения}

В динамике хранения у плодов сливы изученного сорта отмечалось медленное снижение содержания сахаров: 1,7-2,6\%, что объясняется 
равномерным гидролизом сахарозы и относительно стабильным количеством моносахаров. Наименьшее количественное снижение общих углеводов зафиксировано в варианте хранения плодов, обработанных Фитомагом $(1,8 \%)$ и в РГС $(1,7 \%)$

Кислотность слив менялась более динамично, потери кислоты достигали примерно 18-46\%, в зависимости от применяемых способов хранения. В варианте хранения в ОА потребление органических кислот, участвующих в метаболических процессах, было более интенсивным, чем при хранении слив обработанных ингибитором синтеза этилена (рис.2).

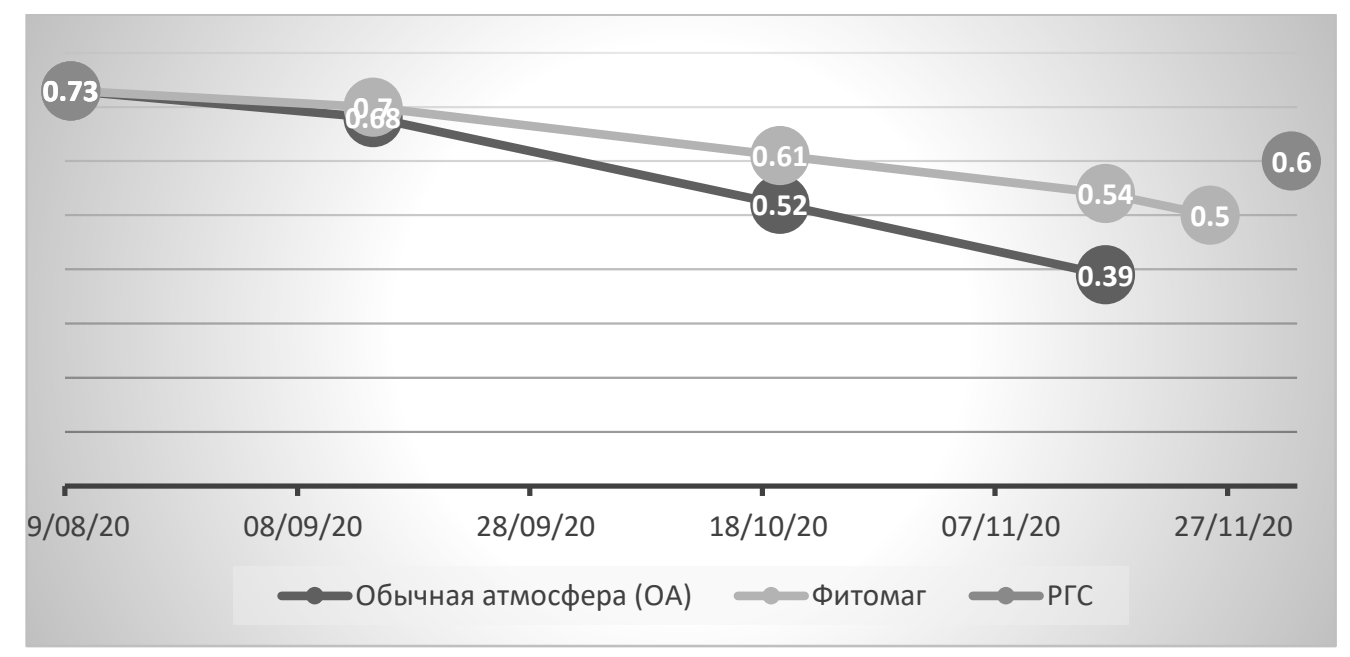

\section{Рис.2. Динамика изменения титруемой кислотности в зависимости от метода хранения}

Одним из важных показателей сохранения качества плодов является содержание сухих веществ. Этот показатель напрямую зависит от физиологического состояния плода. В результате протекания биохимических процессов баланс смещается в пользу деградационных процессов, дыхание усиливается и, таким образом, увеличивается потеря сухого вещества [2, c.127]. В наших исследованиях наименьшие потери были отмечены у плодов сливы, обработанных препаратом Фитомаг и у плодов, хранящихся в РГС (8,0 и 9,0\% соответственно, по сравнению с 15,0\% в ОА) (рис.3). 


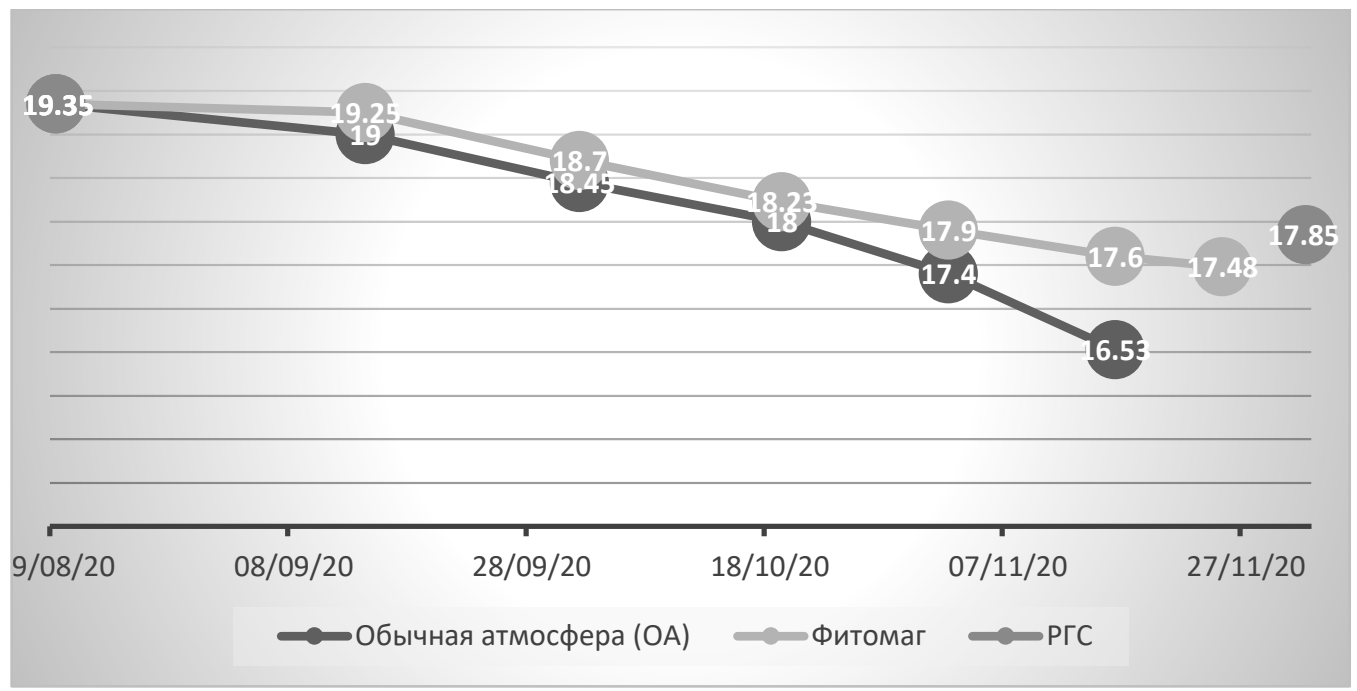

\section{Рис.3. Изменение содержания сухих веществ в зависимости от применяемого метода хранения}

Сравнение биохимических и анатомических показателей в динамике процесса хранения с применением ингибитора синтеза этилена Фитомаг, как и в варианте хранения в РГС, позволило выявить лучшую сохранность клеточных и тканевых структур, а также сахаров, сухих веществ, органических кислот и витамина $\mathrm{C}$, характерных для исследуемых плодов сливы сорта Президент в сравнении с хранением в условиях в ОА.

Исследования проведены в рамках проекта Государственной Программы 20.80009.5107.18 «Целенаправленное формирование иммунной системы и качества плодов поздних сортов сливы, предназначенных для длительного хранения», финансируемой Национальным Агентством по Исследованиям и Развитию.

\section{Список литературы}

1. Beceanu D., Chira A. Tehnologia produselor horticole // București: Editura economică. - 2002. -240 p.

2. Burzo I.,Toma S. și al. Fiziologia plantelor de cultură. // Chișinău: Știința. - 1999. - Vol.3. -349 p.

3. Гудковский В.А. с соавт. Инновационные технологии хранения плодов // Достижения науки и техники АПК. - 2010. - № 8. - С. 72-74.

4. Маринеску М.Ф. Морфологические и гистологические изменения плодов осеннего и зимнего сортов груши в процессе хранения // Conferinţa 
«Ştiinţa în Nordul Republicii Moldova: realizări, probleme, perspective», (Ed. a 3a), 21-22 iunie 2019. - Bălţi: S. n. - 2019. - P.132-136.

5. Причко Т.Г., Германова М.Г. Влияние послеуборочной обработки препаратом SmartFresh на сохранность качества плодов сливы // Новые технологии / New technologies. - 2018. - N 2. - C.136-142.

6. Паушева 3.П. Практикум по цитологии растений // М.: Агропромиздат. - 1988. - 271с.

7. Фурст Г.Г. Методы анатомо-гистологического исследования растительных тканей // Москва: Наука. - 1979. - 155 с.

8. Арасимович В.В., Пономарева Н.П. Обмен углеводов при созревании и хранении плодов яблони // Кишинев: Штиинца. - 1976. - 106 с.

9. Gherghi A. şi al. Biochimia şi fiziologia legumelor şi fructelor // București: Editura Academiei Române. - 2001. - 319 p. 